International Review of Research in Open and Distributed Learning Volume 17, Number 3

April - 2016

\title{
Revising the Community of Inquiry Framework for the Analysis of One-To-One Online Learning Relationships
}

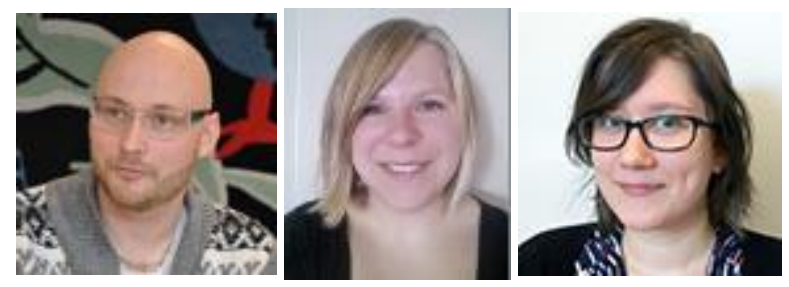

Stefan Stenbom, Malin Jansson, and Annelie Hulkko

KTH Royal Institute of Technology, Sweden

\begin{abstract}
In online learning research, the theoretical community of inquiry framework has been used extensively to analyze processes of inquiry among learners and instructors within a community. This paper examines a special case of community of inquiry consisting of only one learner and one instructor. Together they engage in an online coaching discourse to form a relationship of inquiry. Within these relationships, coachees pass through processes of practical inquiry process while a coach supports the process. In this study, a framework and coding scheme were developed for use in a transcript coding procedure including 3,109 messages from an online coaching case in math for $\mathrm{K}-12$ students. It is found that the elements of cognitive, teaching, and social presence, as well as the newly proposed emotional presence, which outlines a community of inquiry, comprise an effective structure for the analysis of one-to-one online coaching environments. The findings of this exploratory study suggest that a relationship of inquiry framework has the potential to support development of one-to-one online learning.
\end{abstract}

Keywords: community of inquiry, relationship of inquiry, online coaching, one-to-one online learning 


\section{Introduction}

Several tools for analyzing learning processes have been discussed in online education research. One of the most widely researched frameworks is the community of inquiry framework by Garrison, Anderson, and Archer (2000). This theoretical framework represents a process of creating a deep and meaningful (collaborative-constructivist) learning experience. Central to this framework are interdependent aspects of a learning process, which are called elements. The three original elements are cognitive, teaching, and social presence, each of which represent different aspects of the inquiry-based learning process. Two methods of the community of inquiry framework are frequently used to evaluate a learning environment: transcript analysis and a survey study. Transcript analysis involves the examination of transcripts from online text-based educational sessions using a coding scheme, whereas the survey study includes a standardized questionnaire (Anderson, Rourke, Garrison, \& Archer, 2001; Arbaugh et al., 2008; Garrison, Anderson, \& Archer, 2001; Rourke, Anderson, Garrison, \& Archer, 2001a; Swan et al., 2008). The community of inquiry framework, which has been extensively studied and validated, is seen as one of the most prominent models for analyzing online learning (Akyol et al., 2009; Jézégou, 2010). However, the framework has predominantly been used only to examine learning within a group of several students and one or more teachers.

In modern education, large-scale instruction is sometimes combined with more exclusive one-to-one, tutoring-oriented activities. One such learning activity is online coaching. Online coaching is an inquirybased learning activity where a person gets support on a specific subject from a more knowledgeable person using the internet (Hrastinski \& Stenbom, 2013). One example of online coaching is a program called Math Coach, through which $\mathrm{K}-12$ students, using text-based instant messaging complemented by a shared digital whiteboard, can receive help with their math studies from university students studying to become $\mathrm{K}-12$ math teachers.

To conceptualize the one-to-one learning environment of online coaching, Stenbom, Hrastinski, and Cleveland-Innes (2012) introduced the relationship of inquiry framework, which is an adaption of the community of inquiry framework for an online coaching setting. In that study, the items of the community of inquiry survey instrument were modified to a one-to-one context and tested using coaches in the Math Coach program. The community of inquiry framework by Stenbom, Hrastinski, et al. (2012) was selected as a theoretical base for analyzing online coaching due to its capacity to describe the process and components of inquiry-based online learning.

The purpose of this paper is to refine the relationship of inquiry framework. This is done by introducing a transcript coding procedure for systematic analysis of online coaching. The use of transcript analysis is a prominent method in online education (Fahy, Crawford, \& Ally, 2001; Gunawardena, Lowe, \& Anderson, 1997; Neuendorf, 2002). In what follows, the theoretical construct of the relationship of inquiry framework will be presented, followed by use of a transcript coding procedure to test the framework and to gain insight as to the content of the online Math Coach coaching case. 


\section{The Relationship of Inquiry Framework Construct}

In Stenbom, Hrastinski, et al. (2012), the educational relationship of inquiry was proposed for analysis of online coaching by adapting the community of inquiry theoretical framework. The community of inquiry was introduced by Lipman (2003) and put in an online context as "a group of individuals who collaboratively engage in purposeful critical discourse and reflection to construct personal meaning and confirm mutual understanding" (Garrison, 2011, p. 2). It has been argued that the combination of the interdependent elements of cognitive, teaching, and social presence, as well as their categories, gains the understanding of both a group and a one-to-one educational environment (Garrison et al., 2000; Stenbom, Hrastinski, et al., 2012). Their descriptions do, however, need to be slightly modified to reflect the difference between a dyad and a community. The element of emotional presence, suggested by Cleveland-Innes and Campbell (2012), has also been reviewed and recognized in the relationship of inquiry framework (Cleveland-Innes, Stenbom, \& Hrastinski, 2014; Stenbom, Cleveland-Innes, \& Hrastinski, 2012; Stenbom, Cleveland-Innes, \& Hrastinski, 2016). Elements and categories that have been suggested to guide the relationship of inquiry framework are displayed in Table 1.

Table 1

The Relationship of Inquiry Framework

\begin{tabular}{ll}
\hline Element & Category \\
\hline Cognitive presence & Triggering event \\
& Exploration \\
& Integration \\
& Resolution \\
Teaching presence & Design and organization \\
& Facilitating discourse \\
& Direct instruction \\
Social presence & Open communication \\
Emotional presence & Relationship cohesion \\
& Activity emotion \\
& Outcome emotion \\
& Directed affectiveness \\
\hline
\end{tabular}

An educational relationship of inquiry is defined in this paper as a conceptual connection that is built between two persons, here a coachee and a coach that engage in critical discourse. A coachee refers to someone who needs assistance in his or her inquiry in order to construct personal meaning. A coach refers to someone assigned to support a coachee's learning process by developing insight through conversation. Together, these two figures develop a collaborative relationship with the aim to resolve an educational issue.

\section{Cognitive Presence}

Cognitive presence in a relationship of inquiry has been suggested to follow the four phases of the practical inquiry model: a triggering event, exploration, integration, and a resolution (Garrison et al., 2001). The practical inquiry process is assumed to be equivalent for a learner in a dyad and in a community. A triggering event in an online coaching session includes the identification, 
conceptualization, and formulation of a problem or issue, as well as commonly marks when a given conversation changes direction. A triggering event is logically what causes a learner to initiate a discussion, which is expressed during a conversation in the stating of a problem or issue. Exploration includes the review of the learner's previous knowledge, brainstorming, and the exchange of information. It can also be characterized by the self-questioning and doubt of a learner's own ability. Integration consists of combining thoughts in order to make them operational. A typical example of integration (one that can be found in this study) is the existence of mathematical calculations as part of the inquiry process. Finally, resolution refers to the actual solving of a problem or issue, which involves both developing potential solutions and analyzing them.

The primary work of the coach during a learning conversation is to support a coachee's learning experience. It has been noted that, in doing this, the coach can equally gain a deeper understanding of a subject and the process of coaching (Hrastinski, Edman, Andersson, Kawnine, \& Soames, 2012). While coaches can also develop their knowledge through the act of coaching, the focus of this study is limited to the cognitive presence of the coachee in a relationship of inquiry, as the ultimate aim of such coaching is to support the learning of a coachee, not the coach.

\section{Teaching Presence}

Teaching presence has been stated to possess the same categories in a relationship as in a community: design and organization, facilitating discourse, and direct instruction (Anderson et al., 2001). In a relationship of inquiry, the role of a coach is to support the critical inquiry of one person, a coachee. The goal of design and organization is to outline a given inquiry, which means setting goals and methods for learning, as well as selecting software to support the communication. Facilitating discourse involves the monitoring of a coachee's performance by a coach and providing support in order to stimulate cognitive progression. Lastly, direct instruction refers to a coach's sharing of specific subject matter with a coachee, which is often delivered along with procedural steps as to how to move the problem solving process forward.

The process of supporting another person's inquiry can (although an instructor is commonly assigned to it) be assumed to be any member within a community of inquiry (Garrison et al., 2000). However, as peer-teaching is not present in the current empirical case, coachees' teaching presence is excluded from the relationship of inquiry for this study. Furthermore, the organization or facilitation of a discussion by a coachee is considered a part of the cognitive process in this study. 


\section{Social Presence}

Social presence in a relationship of inquiry refers to interpersonal aspects of the relationship (Rourke et al., 2001a). The present study acknowledges the modifications to the definition of social presence established by Cleveland-Innes and Campbell (2012), who consider emotion and affect not only part of social presence, but emotional presence as well. Social presence in a relationship of inquiry is reliant upon open communication and relationship cohesion, both of which can be demonstrated by each individual in a learning dyad.

Open communication refers to participation in risk-free communication within a coaching session, including the involvement and acknowledgement of another person, as well as trivial expressions made in a conversation. Relationship cohesion refers to the progressive development of a collaborativeconstructive relationship between the coach and coachee, which is facilitated by interpersonal connections made with the other individual. In this study, this category has been renamed from community cohesion to relationship cohesion to align with the general change from community to relationship.

\section{Emotional Presence}

Emotional presence refers to the outward expression of emotion, affect, and feeling in a relationship of inquiry, and is a newly suggested component within the community of inquiry framework by ClevelandInnes and Campbell (2012). The component has been developed in research that supports the fundamental role that emotions play in learning processes (Dirkx, 2008; Schutz \& Lanehart, 2002; Sutton \& Wheatley, 2003). In the original version of the community of inquiry framework, emotions were positioned as a part of social presence. However, this positioning has recently been called into question since viewing emotions as a part of social presence limits the analysis of online learning (Garrison \& Akyol, 2013a). Prior studies have confirmed the existence of emotional presence in relationships of inquiry (Cleveland-Innes et al., 2014; Stenbom, Cleveland-Innes, et al., 2012; Stenbom et al., 2016). Expressions of emotion, affect, and feeling are acknowledged as aspects of emotional presence that interrelate with social, cognitive, and teaching presence.

The suggested categories of emotional presence are activity emotion, outcome emotion, and directed affectiveness. Activity emotions and outcome emotions were developed from the control-value theory of achievement emotions (Pekrun, 2006; Pekrun, Goetz, Titz, \& Perry, 2002). Directed affectiveness refers to personal emotions in online communication, as outlined by Derks, Fischer, and Bos (2008), as well as Rourke et al. (2001a). These components can be demonstrated by either person in a learning dyad. An activity emotion is expressed in relation to a given inquiry at hand and refers to an emotional response to the ongoing process and content of critical thinking. An outcome emotion is expressed in relation to the consequence of success or failure to resolve a given issue. Lastly, directed affectiveness refers to an interpersonal emotion or mood during a conversation. 


\section{Method}

In order to test the framework and to gain insight about the process of a one-to-one online coaching setting, a transcript coding procedure was performed.

\section{Participants}

The data of the study were selected from the Math Coach program (www.mattecoach.se), a Swedish program established in 2009 that offers $\mathrm{K}-12$ students mathematics assistance via coaching through textbased instant messaging and a shared digital whiteboard. The typical beginning of a Math Coach conversation is presented in Figure 1. Using this program, a coachee in need of help with a math-related issue can connect with a coach via a Web site to resolve the issue. The coachees who use the program range in age from twelve to nineteen, and the coaches include university students who are studying to become K-12 math teachers. The program's coaches were trained in online coaching, yet were not aware, during this study's data collection period, of the relationship of inquiry framework. The learning activity of the program can be deemed near-synchronous, as a connection between coach and coachee is established in real-time, yet discussion via text enables pauses in communication. Coachees in the program have immediate access to a coach, which is characteristic of synchronous learning. However, a coachee can, when needed, reflect on their work without the tension to immediately respond to a coach, which is a characteristic of asynchronous learning environments. The Math Coach program has utilized two generations of software, the first of which was Windows Live Messenger, and the second (now current) software combines aspects of Microsoft Lync and Microsoft Dynamics CRM in an application developed specifically for the program. All conversations made within the program were saved and archived.

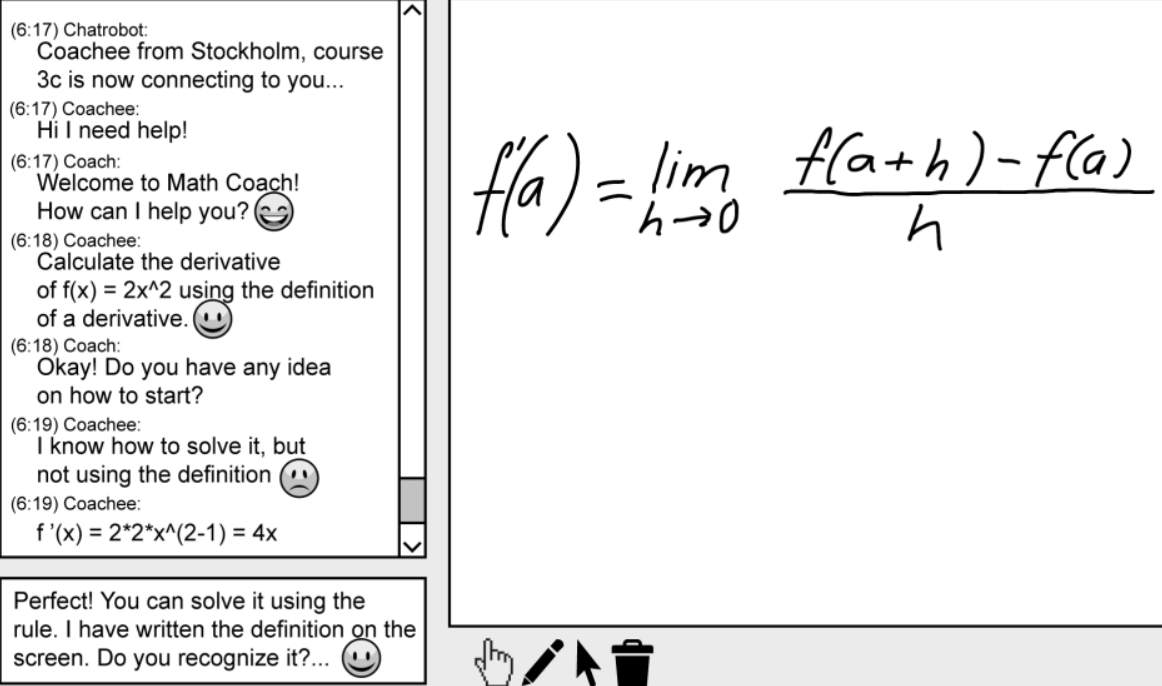

$$
f^{\prime}(a)=\lim _{h \rightarrow 0} \frac{f(a+h)-f(a)}{h}
$$

Figure 1. Example of a math coach conversation. 


\section{Procedures}

Selection of transcripts. Throughout 2012, the Math Coach program included 7,640 conversations, 60 of which were selected for analysis in this study. Half of these conversations were selected randomly (10 per each educational stage of coachee, up to age 12, ages 13 to 16, and ages 16 to 19) in order to test for differences among the groups. An additional 30 conversations were then randomly selected from the entire dataset to keep a potential uneven distribution of groups in the population. No conversation was selected more than once for analysis. For all conversations, the participants gave their informed consent and the content was anonymized.

The transcript coding procedure. The effectiveness of transcript analysis is dependent upon a valid and reliable theoretical framework, coding scheme, and unit of analysis (Garrison, ClevelandInnes, Koole, \& Kappelman, 2006). The community of inquiry theoretical framework, which represents a theoretical point-of-departure in this study, was originally proposed with transcript analysis as empirical method in which the elements and categories are used in a coding scheme (Garrison et al., 2000). Since its creation, the framework has been extensively tested, ensuring its high validity and reliability for transcript analysis (De Wever, Schellens, Valcke, \& Van Keer, 2006; Garrison et al., 2006; Rourke, Anderson, Garrison, \& Archer, 2001b; Swan \& Ice, 2010).

This study utilizes the relationship of inquiry framework and a coding scheme which was developed via a deductive approach using the elements and categories of the relationship of inquiry (Table 1). To assist this process, a review of the community of inquiry framework coding scheme and trial conversations from Math Coach was performed. Following this, indicators and examples from one-to-one online coaching conversations were established for each category. The coding scheme in this study is presented in Table 2.

According to Garrison et al. (2006), the third step in developing a transcript coding procedure is to select the unit of analysis. Research utilizing the community of inquiry framework has commonly used units such as message, paragraph, and sentence, or thematic units. For this study, the message was chosen as the unit of analysis due to the assumption that in near-synchronous, online, text-based coaching, a message typically consists of a few words that together serve a distinguishing purpose. The use of this unit was chosen also because initial coding supported that transcripts could be coded effectively using message as unit of analysis.

The coding of the data was performed both by the second and third author of this study, who were also active coaches in Math Coach. Trial conversations were first examined in order to negotiate and discuss the study's coding scheme. This was then followed by the coders each independently coding half of the conversations. Finally, ten conversations were selected to be coded by both persons in order to enable reliability calculations. All selections of conversations were made randomly. For each message, all categories of the relationship of inquiry coding scheme were reviewed and coded either as existing or not. This permits a message to be coded with more than one category to reflect the interrelation of elements and categories in the framework. Coding at the element level was performed by grouping codes at the category level with their corresponding elements. This was done in order to enable analysis both at the category and element levels. 
Table 2

The Relationship of Inquiry Coding Scheme

\begin{tabular}{|c|c|c|c|}
\hline$\overline{\text { Element }}$ & Category & Indicators (examples only) & Examples \\
\hline \multirow[t]{8}{*}{ Cognitive presence } & Triggering event & Stating a problem, & "Here's the problem: ..." \\
\hline & & changing direction. & "I have another issue." \\
\hline & Exploration & Brainstorming, . . . & "Perhaps I could use..." \\
\hline & & $\begin{array}{l}\text { broad search for insights, } \\
\text { information exchange. }\end{array}$ & $\begin{array}{l}\text { "Am I thinking right here?" } \\
\text { "What is a square root?" }\end{array}$ \\
\hline & Integration & Connecting ideas, & "I can combine ... with ..." \\
\hline & & computations. & $" 7 / 12-x=1 / 4 "$ \\
\hline & Resolution & Achieve solution, & "The answer is 3 !" \\
\hline & & $\begin{array}{l}\text { analysis of solution, } \\
\text { implementation. }\end{array}$ & $\begin{array}{l}\text { "I made a mistake with..." } \\
\text { "Then the apple is cheaper..." }\end{array}$ \\
\hline \multirow[t]{5}{*}{ Teaching presence } & Design and & Establishing interaction, & "What can I help you with?" \\
\hline & organization & $\begin{array}{l}\text { setting parameters for the } \\
\text { inquiry. }\end{array}$ & $\begin{array}{l}\text { "You can type in the textbox or } \\
\text { draw on the whiteboard." }\end{array}$ \\
\hline & Facilitating discourse & Stimulating constructive & "Do you have an idea?" \\
\hline & & inquiry, assessing process. & "What answer did you get?" \\
\hline & Direct instruction & $\begin{array}{l}\text { Providing steps to solution, } \\
\text { summarizing the } \\
\text { discussion. }\end{array}$ & "You should multiply with $10 . "$ \\
\hline \multirow[t]{2}{*}{ Social presence } & Open communication & Acknowledging, & “Okay!”, "Perfect.” \\
\hline & Relationship cohesion & Greetings, vocatives, & "Hello.", "Good luck." \\
\hline \multirow{3}{*}{ Emotional presence } & Activity emotion & & "What should we d, \\
\hline & Outcome emotion & $\begin{array}{l}\text { Emotion about the } \\
\text { consequence of the inquiry }\end{array}$ & "Gah! I have a test on Monday \\
\hline & Directed affectiveness & $\begin{array}{l}\text { Emotion towards the other } \\
\text { person. }\end{array}$ & $\begin{array}{l}\text { this." } \\
\text { "Thank you for helping me!” } \\
\text { “;-), “:-(“, “:-P” }\end{array}$ \\
\hline
\end{tabular}

\section{Results}

Using the relationship of inquiry framework, related coding scheme, and message as the unit of analysis, 60 conversations in the Math Coach program were coded. In total, 3,109 messages were coded, with 4,013 instances of the different categories. This section will first present the reliability calculations of the coding procedure, followed by an analysis of relationships of inquiry in the Math Coach program.

\section{Reliability}

The reliability of the coding procedure was calculated via the coding of ten conversations with 665 coding decisions independently by both of the study's coders. Table 3 displays a matrix of distribution between the two coders in this regard. For transcript coding using the community of inquiry framework, percent agreement and Cohen's kappa are recognized reliability measurements (Cohen, 1960; De Wever et al., 2006; Garrison et al., 2006). In this study, percent agreement and Cohen's kappa were calculated both at 
the category and element levels. At the category level, the percent agreement of this study was .74, and the Cohen's kappa was .71. At the element level, the percent agreement of this study was .89, and the Cohen's kappa was .85.

Table 3

Reliability Matrix

Coder 1

Triggering event

Exploration

Integration

Resolution

จ Design and organization

ङ Facilitation

¿ Direct instruction

Open communication

Relationship cohesion

Activity emotion

Outcome emotion

Directed affectiveness
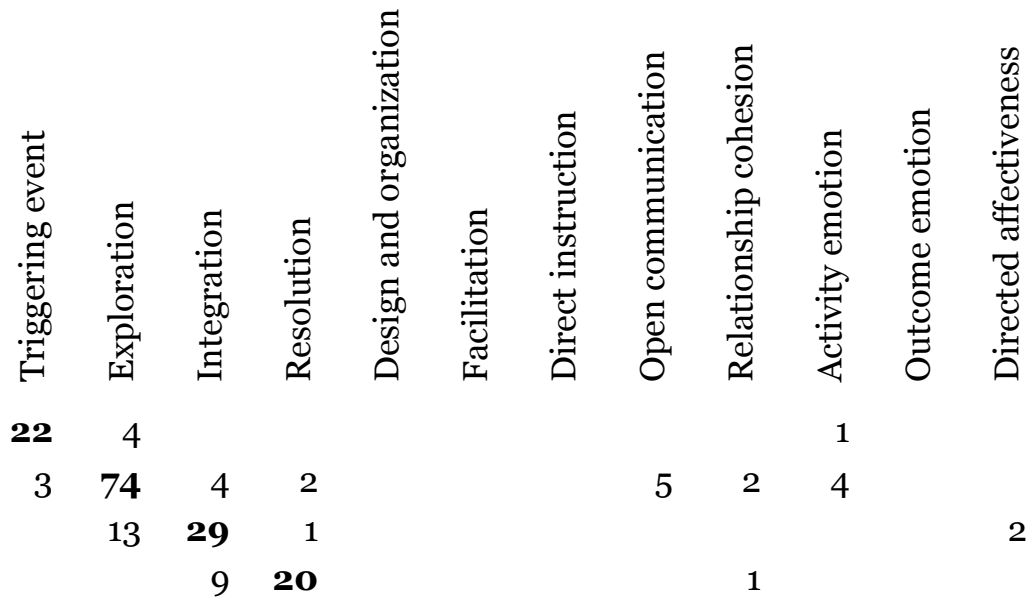

2

1

2

23

12

1

2

\begin{tabular}{|c|c|c|c|c|c|c|c|}
\hline \multirow{4}{*}{2} & & 1 & 3 & 57 & 2 & & 3 \\
\hline & 2 & 4 & 2 & 1 & 40 & 2 & 6 \\
\hline & & & 2 & 1 & & 4 & 2 \\
\hline & & 2 & 4 & 3 & 13 & 1 & 46 \\
\hline
\end{tabular}

\section{Findings}

In calculations the message as the unit of analysis was kept by assigning a message that was coded with more than one code the corresponding portion of the message. A message with one code led to the assignment of 1 point to a corresponding category, with two codes, .5 point were assigned to each corresponding category, with three codes, .33 to each category, and so on. No message was found with more than three categories. For each category and its corresponding element, the mean and standard error of mean per conversation were calculated along with the total sum of codes per message. Together with the examination of the tables of data, statistical analysis was performed to evaluate the findings. As the study's dataset consisted of 60 conversations that were approximately normally distributed, pair sample $t$ tests were used to compare groups of two, and repeated ANOVA with Bonferroni post-hoc tests were used to compare groups larger than two. 
Elements. Table 4 shows the total findings of this study at the element level. Cognitive and teaching presence are more common than social and emotional presence, Wilks' Lambda $=0.725, F(3,57)$ $=7.216, p<.001, \eta^{2}=0.275$, but no differences were found between either cognitive and teaching presence or social and emotional presence. Furthermore, the difference between the total amount of messages sent by a coach and coachee was also evaluated, and no significant difference was found, $t(59)=$ $.24, p=.809$.

Table 4

Descriptive statistics for the Elements

\begin{tabular}{lllll}
\hline Element & Sender & $M$ & $S E$ & Sum \\
\hline Cognitive presence & Coachee & 16.53 & 2.15 & 991.67 \\
Teaching presence & Coach & 15.63 & 2.02 & 937.67 \\
Social presence & Coach & 4.58 & 0.60 & 275 \\
& Coachee & 4.76 & 0.68 & 285.67 \\
Emotional presence & Both & 9.34 & 1.23 & 560.67 \\
& Coach & 5.57 & 0.87 & 334.33 \\
& Coachee & 4.74 & 0.73 & 284.67 \\
All elements & Both & 10.32 & 1.49 & 619 \\
& Coach & 25.78 & 3.11 & 1547 \\
& Coachee & 26.03 & 3.12 & 1562 \\
& Both & 51.82 & 6.15 & 3109 \\
\hline
\end{tabular}

Note. $M=$ Mean, $S E$ = Standard Error of the Mean, Sum = Total Sum of Codes.

Cognitive presence. Table 5 includes the findings in relation to cognitive presence as expressed by coachees. It is significant that exploration is more common than the other categories, Wilks' Lambda = $0.523, F(3,57)=17.336, p<.001, \eta^{2}=0.477$, yet no significant differences were found between triggering event, integration, and resolution.

Table 5

Descriptive Statistics for Cognitive Presence

\begin{tabular}{llll}
\hline Category & $M$ & $S E$ & Sum \\
\hline Triggering event & 2.21 & 0.22 & 132.33 \\
Exploration & 9.38 & 1.30 & 562.67 \\
Integration & 3.04 & 0.63 & 182.67 \\
Resolution & 1.90 & 0.37 & 114 \\
\hline Note. $M=$ Mean, $S E=$ Standard Error of the Mean, Sum =
\end{tabular}

Total Sum of Codes.

Teaching presence. Table 6 shows the findings in relation to teaching presence as articulated by coaches. Direct instructions are significantly most common, Wilks' Lambda $=0.459, F(2,58)=34.202$, $p<.001, \eta^{2}=0.541$, while no differences were found between design and organization and facilitation. 
Table 6

Descriptive Statistics for Teaching Presence

\begin{tabular}{llll}
\hline Category & $M$ & $S E$ & Sum \\
\hline Design and organization & 2.51 & 0.22 & 150.83 \\
Facilitation & 2.41 & 0.48 & 144.33 \\
Direct instruction & 10.71 & 1.51 & 642.5 \\
\hline
\end{tabular}

Note. $M=$ Mean, $S E=$ Standard Error of the Mean, Sum = Total Sum of Codes.

Social presence. Table 7 includes the findings for social presence as demonstrated by both the coach and the coachee. In total, open communication is more common than relationship cohesion, $t(59)=$ $2.76, p=.008$. However, while the coachee predominantly expresses open communication, $t(59)=4.56, p$ $<.001$, the coach puts premium on relationship cohesion, $t(59)=2.19, p=.033$. In terms of the total amount of social presence (shown in Table 4), no differences between coach and coachee were found, $t(59)=0.47, p=.643$.

Table 7

Descriptive statistics for Social Presence

\begin{tabular}{lllll}
\hline Category & Sender & $M$ & $S E$ & Sum \\
\hline Open communication & Coach & 1.86 & 0.28 & 111.33 \\
& Coachee & 3.74 & 0.62 & 224.17 \\
& Both & 5.59 & 0.84 & 335.5 \\
Relationship cohesion & Coach & 2.73 & 0.43 & 163.67 \\
& Coachee & 1.03 & 0.14 & 61.5 \\
& Both & 3.75 & 0.52 & 225.17 \\
\hline \multirow{2}{*}{ Note. $M=$ Mean, $S E=$ Standard Error of the Mean, Sum = Total Sum of Codes. }
\end{tabular}

Emotional presence. Table 8 shows the results for emotional presence as expressed by both the coach and the coachee. A significant difference was found between all elements in this regard, with activity emotion being most common, followed by directed affectiveness, and then outcome emotion, which was rare, Wilks' Lambda $=0.562, F(2,58)=22.573, p<.001, \eta^{2}=0.438$. In comparing the amount of emotion expressed by the coach and the coachee, no significant differences were found for either activity emotion, $t(59)=1.15, p=.257$, outcome emotion, $t(59)=0.56, p=.578$, or directed affectiveness, $t(59)=1,32, p=.192$. 
Table 8

Descriptive Statistics for Emotional Presence

\begin{tabular}{lllll}
\hline Category & Sender & $M$ & $S E$ & Sum \\
\hline Activity emotion & Coach & 3.37 & 0.61 & 202 \\
& Coachee & 2.98 & 0.50 & 179 \\
& Both & 6.35 & 1.06 & 381 \\
Outcome emotion & Coach & 0.11 & 0.06 & 6.33 \\
& Coachee & 0.09 & 0.06 & 5.5 \\
Directed affectiveness & Both & 0.20 & 0.11 & 11.83 \\
& Coach & 2.10 & 0.32 & 126 \\
& Coachee & 1.67 & 0.30 & 100.17 \\
& Both & 3.77 & 0.53 & 226.17 \\
\hline
\end{tabular}

Note. $M=$ Mean, $S E=$ Standard Error of the Mean, Sum = Total Sum of Codes .

Multi-coding. During the coding procedure, 2,241 messages were coded with one category, 832 with two categories, and 36 with three categories. For double-coded messages, Table 9 was developed to display the distribution of codes between categories.

Table 9

Matrix of Double-Coded Messages

Triggering event

Exploration

Integration

Resolution

Design and organization

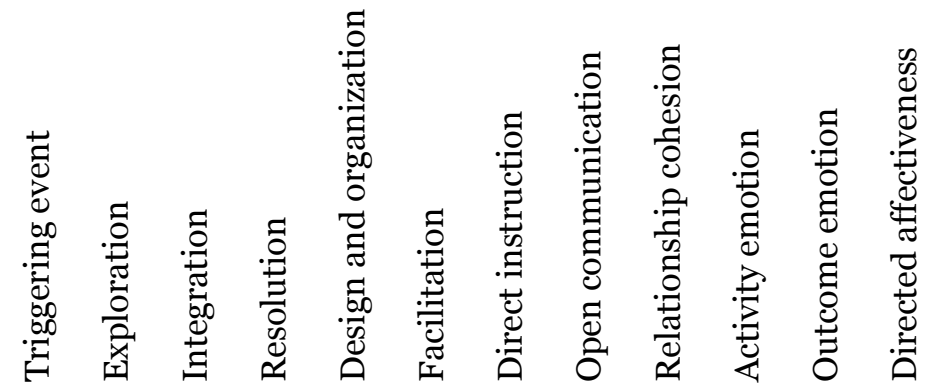

Facilitation

Direct instruction

Open communication

Relationship cohesion

Activity emotion

Outcome emotion

Directed affectiveness

$$
\begin{array}{rrrrrrrrrrr}
0 & & & & & & & & & & \\
0 & 11 & & & & & & & & & \\
0 & 4 & 3 & & & & & & & & \\
0 & 0 & 0 & 0 & & & & & & & \\
0 & 0 & 0 & 0 & 0 & & & & & & \\
0 & 0 & 0 & 0 & 4 & 2 & & & & & \\
0 & 1 & 0 & 0 & 3 & 0 & 3 & & & & \\
19 & 25 & 5 & 1 & 77 & 30 & 158 & 6 & & & \\
9 & 49 & 4 & 7 & 26 & 23 & 62 & 1 & 9 & & \\
0 & 1 & 0 & 0 & 1 & 0 & 1 & 0 & 0 & 0 & \\
8 & 47 & 5 & 5 & 48 & 31 & 89 & 39 & 9 & 6 & 0
\end{array}
$$

In normalizing for the total number of codes per category, three categories stood out. First, for relationship cohesion, $82 \%$ of the total number of codes include one additional category. In directed affectiveness $76 \%$ and in design and organization $68 \%$ had double codes. For triple-coded messages, no calculations were performed, as only $1.2 \%$ of the messages included three codes. 
Educational stage. The conversations of this study were selected from three different education stages in the Swedish school system, including 13 from the stage up to age 12, 26 from ages 13 to 16, and 21 from ages 16 to 19. Several one-way ANOVA with Bonferroni post-hoc tests were performed to test differences among the categories for coaches and coachees based on educational stage. One difference was found in the category of directed affectiveness for coaches. Here it was found that ages 13 to 16 had a significantly higher level than ages 16 to $19, F(2,57)=3.786, p=.029$. All other differences were not significant, which supports the claim that there are, in general, only slight differences in terms of how coaching is done at the different educational stages.

\section{Discussion}

The purpose of this paper was to refine the relationship of inquiry framework, which has been suggested to guide the systematic analysis of one-to-one educational discourse. This was done by adapting the community of inquiry framework for an online coaching setting where the conceptual elements of cognitive, teaching, social, and emotional presence outline the interaction. The data of the study involved a transcript coding procedure in which a framework and coding scheme were used to analyze 3,109 messages in the one-to-one online coaching program Math Coach. To evaluate the value of the coding procedure, reliability was calculated. A measured Cohen's kappa of .71 for categories is considered to represent good agreement beyond chance, while a Cohen's kappa of .85 for elements represents excellent agreement beyond chance (De Wever et al., 2006; Neuendorf, 2002). These calculations imply that the coding procedure of this study had a high level of reliability.

The findings of this study indicate that relationships of inquiry are developed between coaches and the coachees using Math Coach. It is noted that they share the airtime equivalent and that all presences exist in the educational discourse, but cognitive and teaching presence were more often found than social and emotional presence. In comparing the different educational stages, only the directed affectiveness of coaches had a significant difference in relation to the age group of the coachee. Thus, there were almost no differences in terms of how a conversation was conducted by the coachees at the different educational stages.

In terms of cognitive presence, a noticeable advancement of exploration was expected, as the transcript coding procedure of this study only captured the coachees' articulated cognitive processes. Triggering events were found to often be the cause of contacting a coach, and resolutions to math problems were often found to be only expressed in a few messages confirming answers. Furthermore, integration in math issues was found to often involve computations and calculations reported in a fragmentary nature. With regard to teaching presence, it was correctly assumed that the findings for design and organization would be less prominent than in the other categories due to the fact that the learning environment of the program examined in this study is pre-designed in terms of intended use. It was surprising to find direct instruction to be such a prominent component in the program's learning activity compared to facilitation, as this is contradictory to the process of supporting inquiry. A supplementary informal investigation of 
direct instruction messages revealed that slight yet vital changes from directive to facilitative questions in the coaches' questioning could balance this. With regard to social presence, it was anticipated that relationship cohesion would rely heavily on the coach, as coaches are responsible for establishing relationships in the program. However, relationship cohesion was mainly used jointly with other categories to integrate cohesion. In terms of open communication, the coachee articulated mainly trivial expressions. The newly suggested emotional presence was supported in this study's data as being a natural part of educational interactions. Inquiry in the case of Math Coach represented an emotional activity in which directed affectiveness is used to support discourse. The almost complete absence of outcome emotion in this study was surprising, as prior investigations have found strong emotional expressions among coachees regarding assignments and tests.

Due to the nature of transcript coding, this study was limited to the outspoken discourse of online coaching activities. The process of inquiry is, following Dewey (1933), Lipman (1991, 2003), and Garrison (2013), both an individual and social process. Individual reflective thinking and social critical discourse together comprise a collaborative-constructivist learning activity. The research method of transcript coding is effective in terms of capturing the outspoken discourse of an inquiry process, yet not an individual's critical thinking process (Garrison et al., 2006). An example of this is coaches' cognitive processes. Both Hrastinski et al. (2012) and Hrastinski and Stenbom (2013) report that engaging in online coaching offers a learning opportunity not only for coachees, but also for coaches. The coaches of Math Coach, all of whom are studying to become $\mathrm{K}-12$ math teachers, regard the program not merely as extra work, but also as an opportunity to learn how to teach online. The cognitive processes that a coach undertakes when coaching in the program are an important aspect of online coaching, yet these could not be detected in the transcripts of this study, as the coaches rarely discussed their own learning with coachees. Recently, much effort has been committed to examining students' self-regulation and metacognition during learning (Akyol \& Garrison, 2011; Garrison \& Akyol, 2013b). However, these aspects were not considered in the present study, as teaching presence was limited here to be expressed only by coaches. That said, it is assumed that coachees monitor and regulate their learning by engaging in online coaching sessions. Further research is required to address coachees' self-regulation and metacognition.

This paper can be motivated by the opportunity to address Bloom's (1984) 2 sigma problem, arguing that online coaching is an alternative way to realize high order, one-to-one education under practical and realistic conditions. While this study tested the online coaching activities of the Math Coach program only, all conceptualizations were made using general approaches to learning. Therefore, it is hypothesized that the relationship of inquiry can be applied to similar cases given that the learning setting is online, one-to-one, and inquiry-based. This hypothesis should be tested in further research.

The validity of the relationship of inquiry framework rests upon the established quality of the community of inquiry along with the rational modifications to reflect one-to-one learning environments. This study suggests that a one-to-one educational discourse can be conceptualized as a reliable relationship of inquiry. That said further research with a wider application of one-to-one educational settings is needed. This could include for example online tutoring in distance education and analyses of communities of inquiry consisting of multiple relationships. 


\section{Acknowledgements}

We acknowledge the publishing of the coding procedure by Annelie Hulkko and Malin Jansson in their joint master's thesis titled Education through instant messaging: A content analysis in an online coaching project at the KTH Royal Institute of Technology in 2013, which was supervised by Stefan Stenbom.

\section{References}

Akyol, Z., Arbaugh, J. B., Cleveland-Innes, M., Garrison, D. R., Ice, P., Richardson, J. C., \& Swan, K. (2009). A response to the review of the community of inquiry framework. International Journal of E-Learning \& Distance Education, 23(2), 123-136. Retrieved from http://www.ijede.ca/index.php/jde/article/view/630

Akyol, Z., \& Garrison, D. R. (2011). Assessing metacognition in an online community of inquiry. The Internet and Higher Education, 14(3), 183-190. Retrieved from http://dx.doi.org/10.1016/j.iheduc.2011.01.005

Anderson, T., Rourke, L., Garrison, D. R., \& Archer, W. (2001). Assessing teaching presence in a computer conferencing context. Journal of Asynchronous Learning Network, 5(2), 1-17.

Arbaugh, J. B., Cleveland-Innes, M., Diaz, S. R., Garrison, D. R., Ice, P., Richardson, J. C., \& Swan, K. P. (2008). Developing a community of inquiry instrument: Testing a measure of the community of inquiry framework using a multi-institutional sample. The Internet and Higher Education, 11(3), 133-136. Retrieved from http://dx.doi.org/10.1016/j.iheduc.2008.06.003

Bloom, B. S. (1984). The 2 sigma problem: The search for methods of group instruction as effective as one-to-one tutoring. Educational Researcher, 4-16. Retrieved from http://dx.doi.org/10.3102/0013189X013006004

Cleveland-Innes, M., \& Campbell, P. (2012). Emotional presence, learning, and the online learning environment. The International Review of Research in Open and Distributed Learning, 13(4), 269-292. Retrieved from http://www.irrodl.org/index.php/irrodl/article/view/1234

Cleveland-Innes, M., Stenbom, S., \& Hrastinski, S. (2014). The influence of emotion on cognitive presence in a case of online math coaching. Paper presented at the 8th European Distance and E-Learning Network Research Workshop, Oxford, England.

Cohen, J. (1960). A coefficient of agreement for nominal scales. Educational and Psychological Measurement, 2O(1), 37-46. http://dx.doi.org/10.1177/001316446002000104 
De Wever, B., Schellens, T., Valcke, M., \& Van Keer, H. (2006). Content analysis schemes to analyze transcripts of online asynchronous discussion groups: A review. Computers \& Education, 46(1), 6-28. Retrieved from http://dx.doi.org/10.1016/j.compedu.2005.04.005

Derks, D., Fischer, A. H., \& Bos, A. E. (2008). The role of emotion in computer-mediated communication: A review. Computers in Human Behavior, 24(3), 766-785. Retrieved from http://dx.doi.org/10.1016/j.chb.2007.04.004

Dewey, J. (1933). How we think. Mineola, NY: Dover.

Dirkx, J. M. (2008). The meaning and role of emotions in adult learning. New Directions for Adult and Continuing Education, 2008(120), 7-18. Retrieved from http://dx.doi.org/10.1002/ace.311

Fahy, P. J., Crawford, G., \& Ally, M. (2001). Patterns of interaction in a computer conference transcript. The International Review of Research in Open and Distributed Learning, 2(1). Retrieved from http://www.irrodl.org/index.php/irrodl/article/view/36/73

Garrison, D. R. (2011). E-learning in the 21st century: A framework for research and practice. New York: Taylor \& Francis. Retrieved from http://dx.doi.org/10.4324/9780203838761

Garrison, D. R. (2013). Theoretical foundations and epistemological insights. In Z. Akyol \& D. R. Garrison (Eds.), Educational communities of inquiry: Theoretical framework, research and practice. Hershey, PA: IGI Global. Retrieved from http://dx.doi.org/10.4018/978-1-4666-2110-7.choo1

Garrison, D. R., \& Akyol, Z. (2013a). The community of inquiry theoretical framework. In M. G. Moore (Ed.), Handbook of distance education (pp. 104-119). New York: Routledge. Retrieved from http://dx.doi.org/10.4324/9780203803738.ch7

Garrison, D. R., \& Akyol, Z. (2013b). Toward the development of a metacognition construct for communities of inquiry. The Internet and Higher Education, 17(0), 84-89. Retrieved from http://dx.doi.org/10.1016/j.iheduc.2012.11.005

Garrison, D. R., Anderson, T., \& Archer, W. (2000). Critical inquiry in a text-based environment: Computer conferencing in higher education. Internet and Higher Education, 2(2-3), 87-105. Retrieved from http://dx.doi.org/10.1016/S1096-7516(0o)oo016-6

Garrison, D. R., Anderson, T., \& Archer, W. (2001). Critical thinking, cognitive presence, and computer conferencing in distance education. American Journal of distance education, 15(1), 7-23. Retrieved from http://dx.doi.org/10.1080/08923640109527071

Garrison, D. R., Cleveland-Innes, M., Koole, M., \& Kappelman, J. (2006). Revisiting methodological issues in transcript analysis: Negotiated coding and reliability. The Internet and Higher Education, 9(1), 1-8. Retrieved from http://dx.doi.org/10.1016/j.iheduc.2005.11.001 
Gunawardena, C. N., Lowe, C. A., \& Anderson, T. (1997). Analysis of a global online debate and the development of an interaction analysis model for examining social construction of knowledge in computer conferencing. Journal of Educational Computing Research, 17(4), 397-431. Retrieved from http://dx.doi.org/10.219o/7mqv-x9uj-c7q3-nrag

Hrastinski, S., Edman, A., Andersson, F., Kawnine, T., \& Soames, C.-A. (2012). Informal math coaching by instant messaging: Two case studies of how university students coach $\mathrm{K}-12$ students. Interactive Learning Environments, 22(1), 84-96. Retrieved from http://dx.doi.org/10.1080/10494820.2011.641682

Hrastinski, S., \& Stenbom, S. (2013). Student-student online coaching: Conceptualizing an emerging learning activity. The Internet and Higher Education, 16, 66-69. Retrieved from http://dx.doi.org/10.1016/j.iheduc.2012.02.003

Jézégou, A. (2010). Community of inquiry in e-learning: A critical analysis of Garrison and Anderson model. Journal of Distance Education/Revue de l'Education à Distance, 24(3), 1-18. Retrieved from http://www.ijede.ca/index.php/jde/article/view/707

Lipman, M. (1991). Thinking in education (1st ed.). Cambridge: Cambridge University Press.

Lipman, M. (2003). Thinking in education (2nd ed.). Cambridge: Cambridge University Press. Retrieved from http://dx.doi.org/10.1017/cbo9780511840272

Neuendorf, K. (2002). Defining content analysis, In Neuendorf, K (Ed.), Content analysis guidebook. Thousand Oaks, CA: Sage.

Pekrun, R. (2006). The control-value theory of achievement emotions: Assumptions, corollaries, and implications for educational research and practice. Educational Psychology Review, 18(4), 315341. Retrieved from http://dx.doi.org/10.1007/s10648-006-9029-9

Pekrun, R., Goetz, T., Titz, W., \& Perry, R. P. (2002). Academic emotions in students' self-regulated learning and achievement: A program of qualitative and quantitative research. Educational psychologist, 37(2), 91-105. Retrieved from http://dx.doi.org/10.1207/s15326985ep3702 4

Rourke, L., Anderson, T., Garrison, D. R., \& Archer, W. (2001a). Assessing social presence in asynchronous text-based computer conferencing. Journal of Distance Education, 14(2).

Rourke, L., Anderson, T., Garrison, D. R., \& Archer, W. (2001b). Methodological issues in the content analysis of computer conference transcripts. International Journal of Artificial Intelligence in Education (IJAIED), 12, 8-22. Retrieved from http://ijaied.org/pub/951/

Schutz, P. A., \& Lanehart, S. L. (2002). Introduction: Emotions in education. Educational Psychologist, 37(2), 67-68. Retrieved from http://dx.doi.org/10.1207/s15326985ep3702_1 
Stenbom, S., Cleveland-Innes, M., \& Hrastinski, S. (2012). Examining a learning-driven relationship of inquiry discerning emotional presence in online math coaching. Paper presented at the 7 th European Distance and E-Learning Network Research Workshop Research Workshop, Leuven, Belgium.

Stenbom, S., Cleveland-Innes, M., \& Hrastinski, S. (2016). Emotional presence in a relationship of inquiry: The case of one-to-one online math coaching. Online Learning 2o(1). Retrieved from http://olj.onlinelearningconsortium.org/index.php/olj/article/view/563

Stenbom, S., Hrastinski, S., \& Cleveland-Innes, M. (2012). Student-Student Online Coaching as a Relationship of Inquiry: An Exploratory Study from the Coach Perspective. Journal of Asynchronous Learning Networks, 16(5), 37-48.

Sutton, R. E., \& Wheatley, K. F. (2003). Teachers' emotions and teaching: A review of the literature and directions for future research. Educational Psychology Review, 15(4), 327-358. Retrieved from http://dx.doi.org/10.1023/a:1026131715856

Swan, K., \& Ice, P. (2010). The community of inquiry framework ten years later: Introduction to the special issue. The Internet and Higher Education, 13(1-2), 1-4. Retrieved from http://dx.doi.org.focus.lib.kth.se/10.1016/j.iheduc.2009.11.003

Swan, K., Richardson, J. C., Ice, P., Garrison, D. R., Cleveland-Innes, M., \& Arbaugh, J. B. (2008). Validating a measurement tool of presence in online communities of inquiry. E-mentor, 2(24), 112. Retrieved from http://www.e-mentor.edu.pl/artykul/index/numer/24/id/543

\section{Athabasca} University

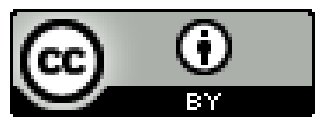

